\title{
Binding mechanisms of maleic hydrazide to homoionic montmorillonites
}

\author{
M.C. Hermosin, I. Roldán and J. Cornejo \\ Instituto de Recursos Naturales y Agrobiologia de Sevilla, C.S.I.C. Apartado 1052, 34080 \\ Seville, Spain
}

\begin{abstract}
Complexes of montmorillonite-maleic hydrazide are prepared and studied by means of X-ray diffraction (XRD) and Fourier transform infrared (FT-IR) spectroscopy techniques. The results of these studies show that the herbicide, maleic hydrazide $(\mathrm{MH})$, is adsorbed onto homoionic montmorillonites in the interlamellar spacing of this mineral, associated, by its carbonyl group, to the exchangeable cation either directly (co-ordinated) or through a waterbridge. When the interlayer cation is $\mathrm{Na}^{+}, \mathrm{Ca}^{2+}$ or $\mathrm{Fe}^{3+}, \mathrm{MH}$ molecules are associated to them both directly and by a water-bridge as the phenoenolic form. When $\mathrm{K}^{+}$is the exchangeable cation the organic molecule is only associated to this cation directly and as the dienolic form.
\end{abstract}

Key words: maleic hydrazide; herbicide; montmorillonites; interaction

\section{INTRODUCTION}

The mechanism of binding of herbicides or other agrochemicals to soil minerals is interesting from the point of view of the soil efficiency and environmental impact and also from the point of view of possible formulations of the herbicide combined with those minerals (Bailey and White, 1970; Niessen, 1982). Effectively the interaction of the herbicide with soil minerals, especially those present in the colloidal fraction, is the ultimate process in determining whether the herbicide exists in the soil solution or in surface waters (Weber, 1970; Allan, 1986).

Maleic hydrazide $(\mathrm{MH})$ is a growth regulator also used as a herbicide whose retention by the soil is determined by its clay fraction content (Hermosín et al., 1987). Furthermore, the different minerals constituting this fraction adsorbed the herbicide to varying extents and with different strengths (Hermosín et al., 1991a). By means of IR technique Hermosín et al., 1991b) have shown that $\mathrm{MH}$ binding to hydroxylated minerals (iron oxides and 
sepiolite) was different from that occurring in montmorillonite. The hydroxylated minerals adsorbed $\mathrm{MH}$ at their external surfaces by surface hydroxyls; whereas in montmorillonite, $\mathrm{MH}$ showed certain accessibility to the interlamellar spacing of this mineral where the herbicide seemed to be associated to the exchangeable cations. Since montmorillonite is one of the most common components of the soil clay fraction and suspended particulate matter in surface waters, it seemed interesting to undertake a more thorough study of the interaction mechanism between maleic hydrazide and montmorillonite saturated with different cations. Infrared spectroscopy has been shown to be a useful tool in showing the binding mechanism of organic molecules to montmorillonite (Hermosín and Perez-Rodriguez, 1981; Hermosín et al., 1985; Sanchez-Martín and Sanchez-Camazano, 1987; Aochi and Farmer, 1988; Micera et al., 1988; McConnell and Hossner, 1989).

The objective of this study was to establish the possible influence of the exchangeable cation in the binding mechanism of the herbicide MH to montmorillonite.

\section{MATERIALS AND METHODS}

The maleic hydrazide used was the pure compound from Fluka and whose structural formula is given by the following equilibrium:
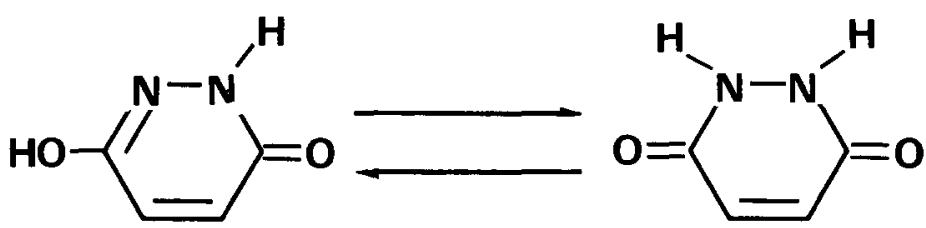

Scheme 1. Structural formula of maleic hydrazide.

The montmorillonite used was the SWy-1 sample of the Clay Mineral Repository (Van Olphen and Fripiat, 1979) which was saturated in $\mathrm{Na}^{+}$, $\mathrm{K}^{+}, \mathrm{Ca}^{2+}$ and $\mathrm{Fe}^{3+}$. The saturation was made by repeated treatment with a $1 \mathrm{~N}$ solution of the corresponding chlorides and by dialysing the final suspension until chloride free. The clay was then air-dried and ground gently by hand.

The preparation of the $\mathrm{MH}-\mathrm{M}^{\mathrm{n}+}-\mathrm{SWy}$ complexes was undertaken by repeated saturations of the mineral sample $(0.2 \mathrm{~g})$ with $4 \mathrm{mM} \mathrm{MH}$ solution until a low amount of $\mathrm{MH}$ was adsorbed. After the final saturation the complexes were rapidly washed with distilled water to remove the excess of the herbicide not adsorbed, air-dried and ground gently by hand. 
The complexes obtained as described above were studied by X-ray diffraction and FT-IR techniques. The X-ray diffractograms of the untreated and MH-treated homoionic montmorillonites were obtained on oriented specimens prepared from a $2 \%$ by weight suspension dried on a glass slide. The FT-IR spectra of the homoionic montmorillonites and their herbicide complexes were obtained on self-supporting film prepared on Mylar paper from a $2 \%$ by weight suspension, air-dried and peeled off. The FT-IR spectrum of $\mathrm{MH}$ was obtained on a $\mathrm{KBr}$ disk.

\section{RESULTS}

The saturation curves for adsorption of $\mathrm{MH}$ onto homoionic montmorillonites are shown in Fig. 1, representing the total amount of $\mathrm{MH}$ adsorbed versus the number of treatments. In this figure the strong influence
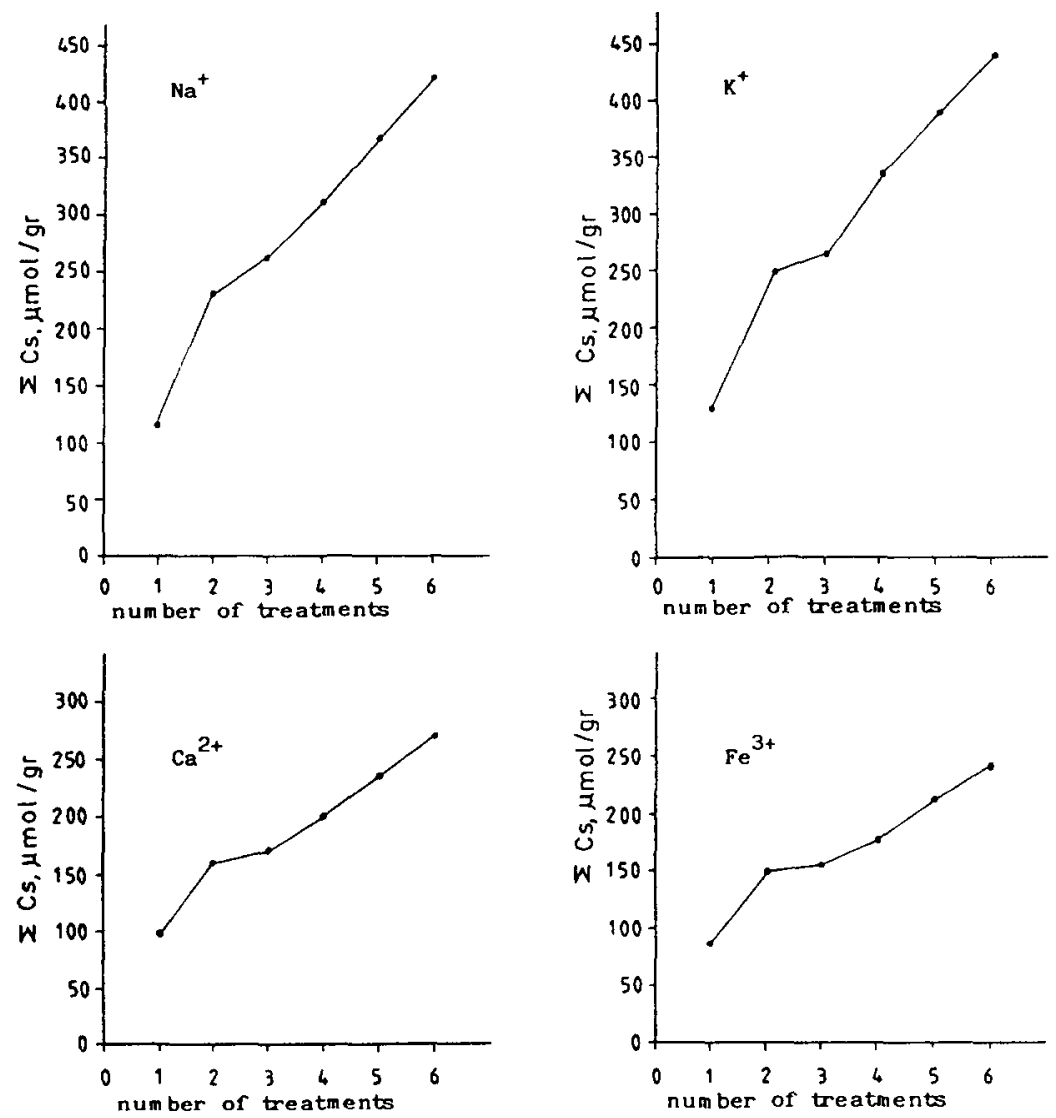

Fig. 1. Curves of saturation with MH for the different homoionic SWy samples. 


\section{TABLE 1}

Basal spacing ( $\AA$ ) of the homoionic SWy samples, air-dried and heated at $110^{\circ} \mathrm{C}$ and amount of $\mathrm{MH}$ adsorbed on the complex

\begin{tabular}{|c|c|c|c|c|c|c|}
\hline \multirow[t]{2}{*}{ Mineral } & \multicolumn{2}{|l|}{ Air-dried } & \multicolumn{2}{|c|}{$110^{\circ} \mathrm{C}$ heated } & \multirow{2}{*}{$\begin{array}{l}\mathrm{Cs}^{\mathrm{a}} \\
(\mu \mathrm{mol} / \mathrm{g})\end{array}$} & \multirow[t]{2}{*}{$n^{\mathrm{b}}$} \\
\hline & Untreated & $\begin{array}{l}\text { MH- } \\
\text { saturated }\end{array}$ & Untreated & $\begin{array}{l}\text { MH- } \\
\text { saturated }\end{array}$ & & \\
\hline $\mathrm{Na}^{+}-\mathrm{SWy}$ & 12.40 & 12.30 & 11.19 & 12.30 & 418.6 & 0.55 \\
\hline $\mathbf{K}^{+}-\mathbf{S W y}$ & 11.19 & 12.11 & 10.40 & 11.78 & 439.7 & 0.58 \\
\hline $\mathrm{Ca}^{2+}-\mathrm{SWy}$ & 15.56 & 14.73 & 13.33 & 14.49 & 270.2 & 0.70 \\
\hline $\mathrm{Fe}^{3+}-\mathrm{SWy}$ & 12.99 & 12.27 & 11.94 & 12.27 & 244.4 & 0.95 \\
\hline
\end{tabular}

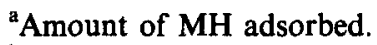

${ }^{b}$ Number of $\mathrm{MH}$ molecule per exchangeable cation.

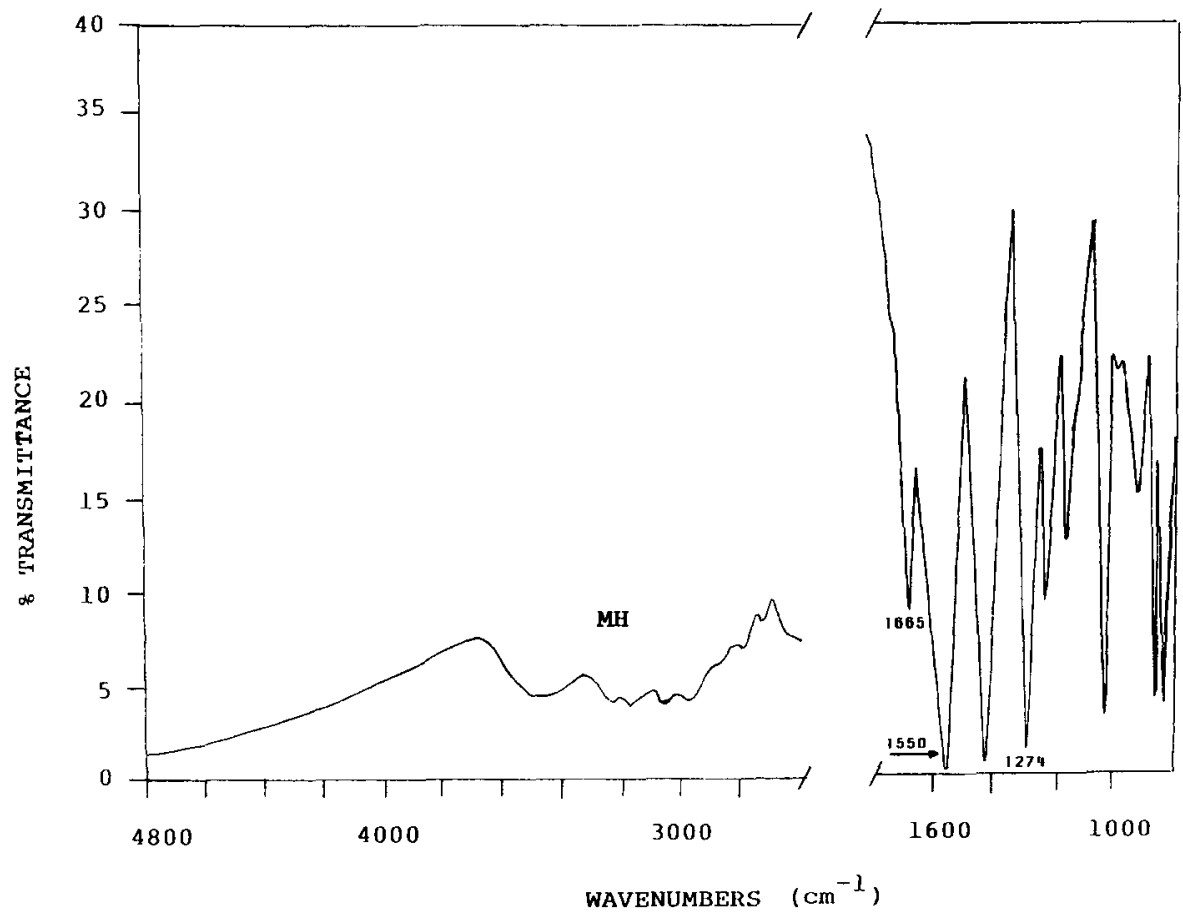

Fig. 2. FT-IR spectrum of pure $\mathrm{MH}$. 
of the exchangeable cations can be observed, as shown by the increasing amounts of $\mathrm{MH}$ adsorbed as follows: $\mathrm{Fe}^{3+}-\mathrm{SWy}<\mathrm{Ca}^{2+}-\mathrm{SWy}<\mathrm{Na}^{+}<$ $\mathrm{K}^{+}-\mathrm{SWy}$. This fact was also reported for adsorption-desorption studies (Hermosin et al., 1991a) and was suggested as evidence of interlamellar adsorption on this mineral.

The total amount of MH adsorbed by successive saturation on each sample is reported in Table 1 as Cs, which increased as the exchangeable cation charge decreased. Effectively as the cation charge decreased, the layercation-layer attraction decreased and the accessibility to the interlayer spacing for MH molecules became easier. The complexes obtained by the above procedure were assayed by X-ray diffraction and IR spectroscopy techniques.

Table 1 shows the basal spacing values, $\mathrm{d}_{001}$, calculated from the X-ray diffractograms, for all the original and $\mathrm{MH}$-saturated samples air-dried and heated at $110^{\circ} \mathrm{C}$. No significative differences were found for $d_{001}$ values between air-dried untreated and $\mathrm{MH}$ treated samples. After heating at $110^{\circ} \mathrm{C}$ the untreated samples spacing slightly decreased due to interlamellar water

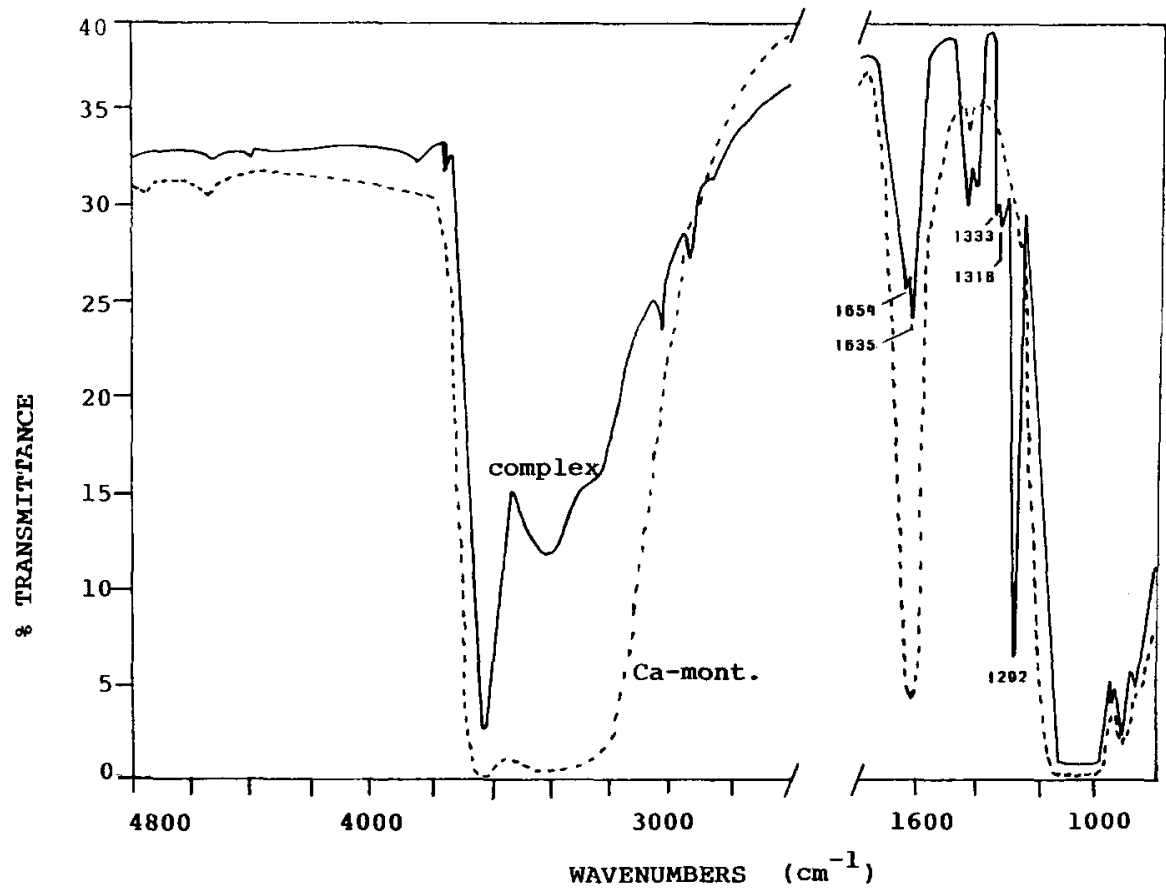

Fig. 3. FT-IR spectra of original Ca-SWy (dotted line) and MH-Ca-SWy complex (solid line). 
loss but the MH-montmorillonite complexes did not show this decrease indicating that some interlamellar adsorption of $\mathrm{MH}$ molecules had occurred. Table 1 also shows the number of MH molecules adsorbed for each exchangeable cation which has been calculated from the total amount of MH adsorbed (Cs $\mu \mathrm{mol} / \mathrm{g}$ ) and the cation exchangeable capacity (CEC) of SWy-1 sample (Van Olphen and Fripiat, 1979: CEC $=76$ mequiv. $/ 100 \mathrm{~g}$ ).

The FT-IR spectrum of pure MH is shown in Fig. 2 and the spectra of the organo-clay complexes besides the original mineral samples are shown in Figs 3 and 4 . The main bands of these spectra are summarized in Table 2 and were assigned according to Bellamy (1980a) to the organic compound, and to Farmer (1974) to the montmorillonite.

The spectra of $\mathrm{MH}-$ mineral complexes showed bands corresponding to MH but shifted and, in some cases, split compared with the pure herbicide, suggesting certain surface-chemical binding that changed the energy of some bonds of the MH molecule. These band changes were different for the different homoionic samples of SWy samples. The most important features were observed on Amide I $\left(1665 \mathrm{~cm}^{-1}\right)$, II $\left(1550 \mathrm{~cm}^{-1}\right)$ and III $\left(1274 \mathrm{~cm}^{-1}\right)$ bands and $\mathrm{N}-\mathrm{H}$ stretching $\left(3457 \mathrm{~cm}^{-1}\right)$, although changes were also observed in

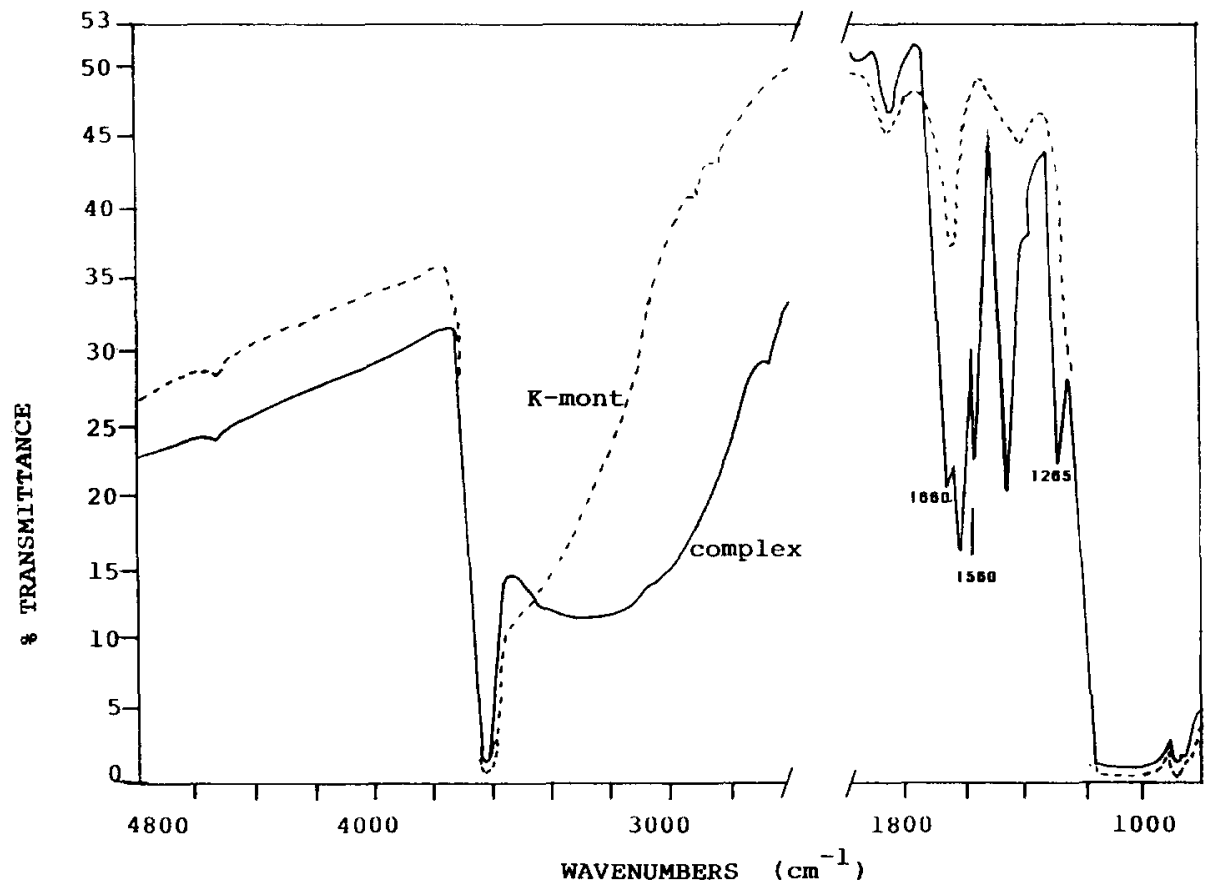

Fig. 4. FT-IR spectra of original K-SWy (dotted line) and MH-K-SWy complex (solid line). 
Infrared frequencies of $\mathrm{MH}$ and $\mathrm{MH}-$ mineral complexes in $\mathrm{cm}^{-1}$

\begin{tabular}{|c|c|c|c|c|c|}
\hline & MH & $\mathrm{Na}-\mathrm{SWy}$ & $\mathrm{Ca}-\mathrm{SWy}$ & $\mathrm{Fe}-\mathrm{SWy}$ & K-SWy \\
\hline \multirow[t]{2}{*}{$\delta \mathrm{O}-\mathrm{H}$} & 1200 & & & & \\
\hline & & 1292 & 1292 & 1286 & \\
\hline$\nu \mathrm{C}-\mathrm{N}$ Amide & 1274 & 1318 & 1318 & 1344 & 1265 \\
\hline \multirow[t]{2}{*}{$\delta \mathrm{N}-\mathrm{H}$ III } & & 1333 & 1333 & 1352 & \\
\hline & & 1406 & 1406 & 1420 & \\
\hline$\nu \mathrm{C}-\mathrm{O}$ & 1411 & 1420 & 1420 & 1437 & 1435 \\
\hline$\nu \mathrm{C}=\mathrm{C}$ & & 1437 & 1437 & 1444 & \\
\hline$\delta \mathrm{N}-\mathrm{H}$ Amide & 1550 & & \multicolumn{2}{|c|}{$\nu \mathrm{C}-\mathrm{N}$ II } & 1560 \\
\hline $\begin{array}{l}\nu \mathrm{C}-\mathrm{N} 11 \\
\nu \mathrm{C}=\mathrm{C}\end{array}$ & 1579 & & & & 1619 \\
\hline$\nu \mathrm{C}=\mathrm{O}$ Amide $\mathrm{I}$ & & 1640 & 1635 & 1635 & \\
\hline \multirow[t]{2}{*}{${ }_{\nu} \mathrm{C}=\mathrm{N}$} & 1665 & $\begin{array}{l}1654 \\
(1650)^{a}\end{array}$ & $\begin{array}{l}1654 \\
(1647)^{\mathrm{a}}\end{array}$ & $\begin{array}{l}1650 \\
(1640)^{\mathrm{a}}\end{array}$ & 1660 \\
\hline & & 2891 & 2950 & & \\
\hline$\nu \mathrm{C}-\mathrm{H}$ & 2969 & $\begin{array}{l}3010 \\
(3390)^{b}\end{array}$ & $\begin{array}{l}3067 \\
(3400)^{b}\end{array}$ & 3067 & \\
\hline$\nu \mathrm{N}-\mathrm{H}$ & 3457 & 3221 & 3224 & 3224 & 3200 \\
\hline
\end{tabular}

${ }^{\mathrm{a}} \mathrm{\delta} \mathrm{O}-\mathrm{H}$.

${ }^{b} \mathrm{O}-\mathrm{H}$ of interlayer water.

the combined modes $\nu \mathrm{C}-\mathrm{O}+\nu \mathrm{C}=\mathrm{C}$ band $\left(1411 \mathrm{~cm}^{-1}\right)$ and $\nu \mathrm{C}=\mathrm{C}$ band $\left(1579 \mathrm{~cm}^{-1}\right)$. With respect to the adsorbent, changes were observed in the water-bending and stretching modes of water molecules associated to the exchangeable cation of the homoionic montmorillonites (interlayer water).

The most relevant change observed for all complexes was the decrease in frequency of the Amide I band, which is fundamentally due to $\nu \mathrm{C}=\mathrm{O}$, from 1665 to $1660-1640 \mathrm{~cm}^{-1}$ indicating a weakness of the $\mathrm{C}=\mathrm{O}$ bond, because the stretching mode of a bond decreases in frequency when it is imvolved in a H-bridge. (Bellamy, 1980b). The Amide III band $\left(1274 \mathrm{~cm}^{-1}\right)$, which is a combination of the two modes $\nu \mathrm{C}-\mathrm{N}$ and $\delta \mathrm{N}-\mathrm{H}$, increased in frequency and split for all cases studied except for $\mathrm{K}^{+}-\mathrm{SWy}$, where it decreased slightly, as shown in Figs 3 and 4, respectively, and in Table 2. The Amide II band $\left(1550 \mathrm{~cm}^{-1}\right)$, which is also a combination of the $\delta \mathrm{N}-\mathrm{H}$ and $\nu \mathrm{C}-\mathrm{N}$ modes, almost disappeared for $\mathrm{Na}^{+}, \mathrm{Ca}^{2+}$ and $\mathrm{Fe}^{3+}$ but for $\mathrm{K}^{+}-\mathrm{SWy}$ slightly increased in frequency. Similar changes were observed for different amides adsorbed on montmorillonite by Tahoun and Mortland (1966). A decrease in frequency and broadening of the $\mathrm{N}-\mathrm{H}$ band $\left(3457 \mathrm{~cm}^{-1}\right)$ was also observed for $\mathrm{MH}-\mathrm{SWy}$ complexes, especially for $\mathrm{MH}-\mathrm{K}^{+}-\mathrm{SWy}$ (Fig. 4). 
With regard to the adsorbent, changes were observed on MH-SWy, for interlayer water vibrations, except for the potassium-saturated sample. For SWy complexes a great decrease in the intensity of water-bands at 3420 and $1635 \mathrm{~cm}^{-1}$ indicated some replacement of $\mathrm{H}_{2} \mathrm{O}$ by $\mathrm{MH}$ molecules. Also some displacements of the frequency of these bands of $\mathrm{MH}-\mathrm{SWy}$ complexes were observed: $\nu \mathrm{OH}$ decreased and $\delta \mathrm{OH}$ increased from 3420 to 3400-3390 $\mathrm{cm}^{-1}$ and from 1635 to $1640-1650 \mathrm{~cm}^{-1}$, respectively, indicating the formation of water-bridges (Bellamy, 1980b). These changes corresponding to clay water, which are associated to the exchangeable cation, were not found for $\mathrm{MH}-\mathrm{K}^{+}-\mathrm{SWy}$ complex. The potassium cation, as shown in the spectrum of the original $\mathrm{K}^{+}-\mathrm{SWy}$ sample (Fig. 4) had a very low number of water molecules associated to it due to its low polarizing power and hence low hydration affinity.

From the IR spectra results the MH-montmorillonite complexes can be considered in two groups: (1) $\mathrm{Na}^{+}-, \mathrm{Ca}^{2+}-$ and $\mathrm{Fe}^{3+}-\mathrm{SWy}$ and (2) $\mathrm{K}^{+}-\mathrm{SWy}$.

\section{DISCUSSION}

The X-ray results (Table 1), and the high adsorption capacity found, (Fig. 1) seemed to confirm that MH was adsorbed at the interlamellar spaces of the SWy samples. The amount of MH adsorbed, expressed as the number of MH molecules per exchangeable cation, $n$ (Table 1), was found to be less than 1 for all cases indicating that possibly non-homogeneously distributed complexes were formed in all interlamellar spaces of these clays. This was also indicated by the low number of $d_{001}$ reflections ( 1 or 2$)$ observed in the $\mathrm{X}$-ray diffractograms, which were better resolved for $\mathrm{MH}-\mathrm{Ca}^{2+}-\mathrm{SWy}$ and $\mathrm{MH}-\mathrm{Fe}^{3+}-\mathrm{SWy}$ complexes having $n$ values closer to 1 (Table 1). For all complexes the $d_{001}$ values showed an increase of the width of a silicate layer $(9.6 \AA)$ of approximately $3 \AA$ which corresponds to a parallel orientation of the organic ring between the silicate layers (Serratosa, 1965). The larger expansion (Table 1) corresponded to $\mathrm{Na}^{+}-, \mathrm{Ca}^{2+}-$ and $\mathrm{Fe}^{3+}-\mathrm{SWy}$ complexes because, as it will be seen below, these samples retained part of the water associated to the exchangeable cation besides the MH molecules. $\mathrm{K}^{+}-\mathrm{SWy}$ showed lower expansion because this complex has no water in the interlayer spaces. As shown in Figs. 3 and 4 and in Table 2 the MH-mineral complexes spectra were similar for $\mathrm{Na}^{+}-, \mathrm{Ca}^{2+}-$ and $\mathrm{Fe}^{3+}-\mathrm{SWy}$ and different for $\mathrm{K}^{+}-\mathrm{SWy}$ and this will be considered in the discussion below. The FT-IR spectra of MH complex of $\mathrm{Na}^{+}-, \mathrm{Ca}^{2+}-$ and $\mathrm{Fe}^{3+}-\mathrm{SWy}$ showed a decrease in the amount of water molecules associated to the exchangeable cation indicating their substitution by polar MH molecules. The absorption bands of this water shifted to higher frequency $\delta \mathrm{OH}$ (from 1635 to 
$1640-1650 \mathrm{~cm}^{-1}$ ) and to lower frequency $\nu$ OH (from 3420 to $3400-3390$ $\mathrm{cm}^{-1}$ ) which suggested that some of the remaining water molecules were $\mathrm{H}$ bonded to MH molecules making a water-bridge (Bellamy, 1980b). This type of bond has been shown by other authors for other polar molecules (Serratosa, 1968; Sanchez-Camazano and Sanchez-Martín, 1983; Tahoun and Mortland, 1966; Sanchez-Martín and Sanchez-Camazano, 1987; McConnell and Hossner, 1989).

The most important feature observed for IR bands of MH upon adsorption on $\mathrm{Na}^{+}, \mathrm{Ca}^{2+}$ and $\mathrm{Fe}^{3+}$ homoionic SWy samples (Fig. 3, Table 2) were on Amide I, II and III bands. The $\nu \mathrm{C}=\mathrm{O}$ was split and lowered in frequency. The frequency lowering indicates that this group of the $\mathrm{MH}$ molecule is bound to the exchangeable cation either directly (coordinated) or through a water-bridge (Tahoun and Mortland, 1966). In these complexes both binding mechanisms seemed to occur. Effectively the complex $1654 \mathrm{~cm}^{-1}$ band has three components: 1635 and $1654 \mathrm{~cm}^{-1}$, corresponding to $\nu \mathrm{C}=\mathrm{O}$ directly water-bridged and bound to the exchangeable cation; while at $1650 \mathrm{~cm}^{-1}$ the water-bending mode of the water molecules is found. The Amide III band $(\nu \mathrm{C}-\mathrm{N}+\delta \mathrm{NH})$ at $1274 \mathrm{~cm}^{-1}$ increased and split in frequency because of the increase of the double bond character of the $\mathrm{C}-\mathrm{N}$ bond (Tahoun and Mortland, 1966). The great intensity of $1292 \mathrm{~cm}^{-1}$ band in these MH-SWy complexes $\left(\mathrm{Na}^{+}, \mathrm{Ca}^{2+}\right.$ and $\left.\mathrm{Fe}^{3+}\right)$ could be due to the coupling of the Amide III band with $\delta \mathrm{OH}$, the phenolic form of $\mathrm{MH}$, bonded to the oxygens of the basal plane of the silicate layer. The Amide II band $(\delta \mathrm{NH}+\nu \mathrm{C}-\mathrm{N})$ at 1550 $\mathrm{cm}^{-1}$ almost disappeared, probably (although is not the only reason) because $\mathrm{NH}$ groups are $\mathrm{H}$-bonded to the basal oxygen atoms as suggested also by the decrease in frequency of $\nu$ NH (Fig. 3, Table 2). The MH bands observed on these $\mathrm{MH}$ complexes $\left(\mathrm{Na}^{+}, \mathrm{Ca}^{2+}\right.$ and $\left.\mathrm{Fe}^{3+}-\mathrm{SWy}\right)$ indicated that $\mathrm{MH}$ molecules are the phenoenolic form, as in crystalline $\mathrm{MH}$.

As shown in Fig. 4 and Table 2, the $\mathrm{MH}-\mathrm{K}^{+}-\mathrm{SWy}$ complex is different from the other homoionic forms of SWy studied. The Amide I, II and III band shifted slightly $\left(5-10 \mathrm{~cm}^{-1}\right)$ with respect to pure $\mathrm{MH}$, however an increase in frequency of $\nu \mathrm{C}-\mathrm{O}+\nu \mathrm{C}=\mathrm{C}$ band at $1411 \mathrm{~cm}^{-1}$ and in $\nu \mathrm{C}=\mathrm{C}$ band at $1579 \mathrm{~cm}^{-1}$ and a great decrease and broadening of $\nu \mathrm{NH}$ were observed. All these changes seem to suggest that $\mathrm{MH}$ is adsorbed as the dienolic form, bonded directly to potassium ion in the interlamellar spaces. Thus $\nu \mathrm{C}-\mathrm{O}+\nu \mathrm{C}=\mathrm{C}$ band increased from $1411 \mathrm{~cm}^{-1}$ to $1435 \mathrm{~cm}^{-1}$ (Table 2; acquiring only a $\mathrm{C}=\mathrm{C}$ conjugated with $\mathrm{C}=\mathrm{O}$ character (Bellamy, 1980), which also produced an increase of the ring breathing frequency $\nu \mathrm{C}=\mathrm{C}$ from 1579 to $1619 \mathrm{~cm}^{-1}$ (Table 2). This also explains the lowering of the Amide III band from 1274 to $1265 \mathrm{~cm}^{-1}$ due to the increase in single bond character of $\mathrm{C}-\mathrm{N}$ and the increase in frequency of Amide II $(\delta \mathrm{N}-\mathrm{H})$ from 1550 to $1560 \mathrm{~cm}^{-1}$ due to $\mathrm{NH}$ group bonding to basal oxygen atoms of the 

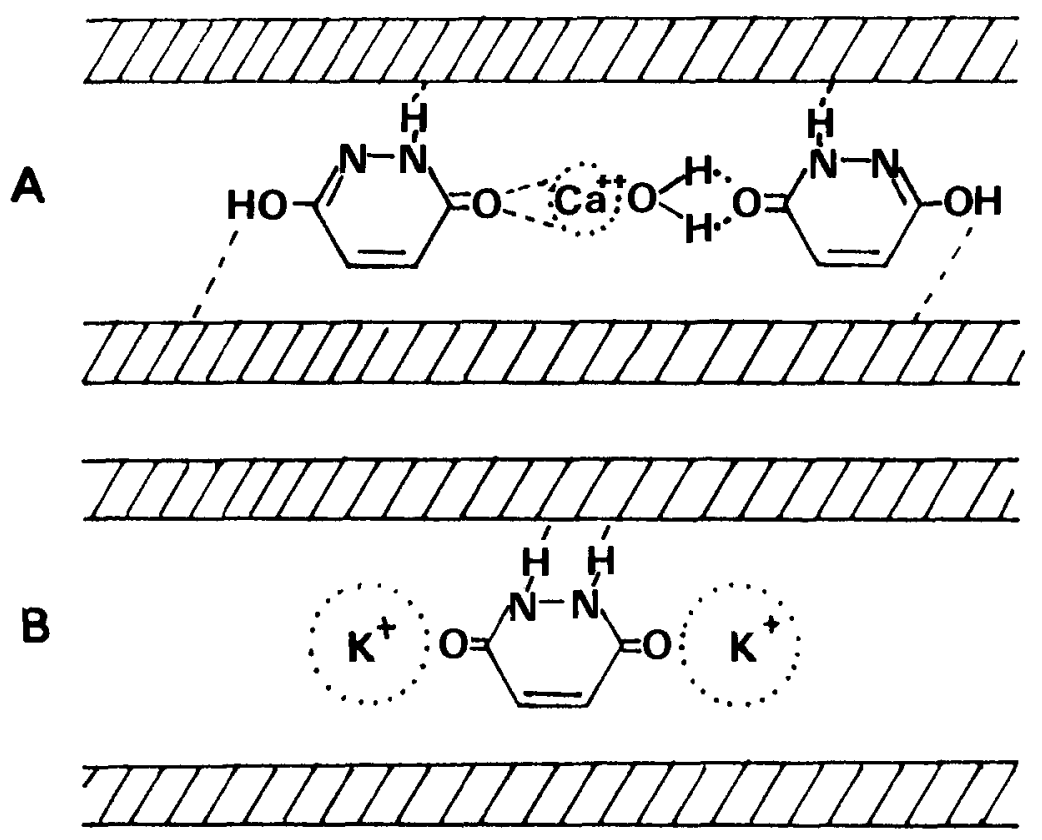

Fig. 5. Mechanism of MH binding to the exchangeable cation in montmorillonite interlayer.

silicate layers. This is also supported by the decrease and broadening observed for $\nu \mathrm{NH}$ at $3224 \mathrm{~cm}^{-1}$ in this complex (Fig. 4, Table 2).

According to the results discussed above, Fig. 5 shows the mechanisms of MH binding to the exchangeable cation $\mathrm{Na}^{+}, \mathrm{Ca}^{2+}$ and $\mathrm{Fe}^{3+}$ (Fig. 5A) and for $\mathrm{K}^{+}$(Fig. 5B) in the SWy sample.

\section{ACKNOWLEDGEMENTS}

This work was partially supported by CICYT through Project No. NAT 90-910 and by Junta de Andalucia through the Research Group No. 4092.

\section{REFERENCES}

Allan, R.J., 1986. The role of particulate matter in the transport and burial of contaminants in aquatic ecosystems. In: B.T. Hart (Ed.), Water Quality Managements: The Role of Particulate Matter in the Transport and Fate of Pollutants. Water Studies Center, Chisholm Institute of Technology, Melbourne, pp. 1-57.

Aochi, Y. and W.J. Farmer, 1988. Spectroscopic evidence for a copper-picloran complex on Cu(II)-saturatad and Cu(II)-hydrous oxide coated montmorillonite. Soil Sci. Soc. Am. J., 52: $1265-1270$. 
Bailey, G.W. and J.L. White, 1970. Factors influencing the adsorption, desorption and movement of pesticides in soils. Res. Rev., 32: 29-92.

Bellamy, L.J., 1980a. The Infrared Spectra of Complex Molecules, Vol. 1. Chapman and Hall, London and New York.

Bellamy, L.J., 1980b. The Infrared Spectra of Complex Molecules, Vol. 2. Chapman and Hall, London and New York.

Farmer, V.C., 1974. The Layer Silicates. In: V.C. Farmer (Ed.), The Infrared Spectra of Minerals. Mineralogical Society London Monograph no. 4: 331-363.

Hermosín, M.C. and J.L. Perez-Rodriguez, 1981. Interaction of chlordimeform with clay minerals. Clay Clay Mineral., 29: 143-152.

Hermosín, M.C., J. Cornejo and J.L. Perez Rodriguez, 1985. Thermal stability of chlordimeform-montmorillonite complex. Clay Clay Mineral., 20: 153-159.

Hermosin, M.C., J. Cornejo and J.L. Perez Rodriguez, 1987. Adsorption and desorption of maleic hydrazide as a function of soil properties. Soil Sci., 144: 250-256.

Hermosín, M.C., I. Roldán and J. Cornejo, 1991a. Adsorption-desorption of maleic hydrazide on mineral soil components. J. Environ. Sci. Health, B26 (2): 165-183.

Hermosin, M.C., I. Roldán and J. Cornejo, 1991b. Maleic hydrazide interactions with soil clay surfaces. Chemosphere, 23: 473-483.

McConnell, J.S. and L.R. Hossner, 1989. X-ray diffraction and infrared spectroscopic studies of adsorbed glyphosate. J. Agric. Food Chem., 37: 555-560.

Micera, G., A. Pusino, C. Gessa and S. Petretto, 1988. Interaction of fluazifop with Al-, $\mathrm{Fe}^{3+}$ and $\mathrm{Cu}^{2+}$-saturated montmorillonite. Clay Clay Mineral., 36: 354-358.

Niessen, H., 1982. Formulation aids. In: K.H. Buchel (Ed.), Chemistry of Pesticides. John Wiley and Sons, New York, pp. 406-413.

Sanchez-Camazano, M. and M.J. Sanchez-Martín, 1983. Factors influencing interactions of organophosphorous pesticides with montmorillonite. Geoderma, 29: 107-118.

Sanchez-Martin, M.J. and M. Sanchez-Camazano, 1987. Adsorption of cloridazone by montmorillonite. Chemosphere, 16: 937-944.

Serratosa, J.M., 1968. Infrared study of benzonitrile $\left(\mathrm{C}_{6} \mathrm{H}_{5}-\mathrm{CN}\right)$-mont. The montmorillonite complexes. Am. Mineral., 53: 1244-1251.

Van Olphen, H. and J. Fripiat, 1979. Data Handbook for Clay Materials and other Non Metallic Minerals. Pergamon Press, Oxford.

Weber, J.B., 1970. Mechanisms of adsorption of $S$-triazines by clay colloids and factors affecting plant availability. Res. Rev., 32: 93-130. 